\title{
Chronic lymphocytic leukemia-associated cholangiopathy
}

\author{
Jake Mann ${ }^{1}$, Stefan Urbanski MD FRCPC ${ }^{2}$, Johannes Lategan MB ChB MMed ${ }^{3}$, Mark G Swain MD MSc FRCPC ${ }^{4}$
}

\section{CASE PRESENTATION}

A 41-year-old woman with untreated low-grade B-cell chronic lymphocytic leukemia (CLL), diagnosed by peripheral blood flow cytometry nine months previously (white blood cell count $14.7 \times 10^{9} / \mathrm{L}$; lymphocytes $10.4 \times 10^{9} / \mathrm{L}$ ), was referred to the University of Calgary Liver Unit (Calgary, Alberta) with abnormal serum levels of liver enzymes: alkaline phosphatase $138 \mathrm{U} / \mathrm{L}$ to $204 \mathrm{U} / \mathrm{L}$ (normal lower than $115 \mathrm{U} / \mathrm{L}$ ); aspartate aminotransferase $42 \mathrm{U} / \mathrm{L}$ (normal lower than $32 \mathrm{U} / \mathrm{L}$ ); alanine aminotransferase $53 \mathrm{U} / \mathrm{L}$ (normal range $1 \mathrm{U} / \mathrm{L}$ to $40 \mathrm{U} / \mathrm{L}$ ); and gamma-glutamyl transferase $115 \mathrm{U} / \mathrm{L}$ to $187 \mathrm{U} / \mathrm{L}$ (normal lower than $35 \mathrm{U} / \mathrm{L}$ ). She was asymptomatic and her medical history consisted only of hypothyroidism treated with thyroxine. She was taking no other regular medications or herbal supplements. She consumed one to two standard alcoholic beverages per week. The physical examination was normal (body mass index $21 \mathrm{~kg} / \mathrm{m}^{2}$ ). A screen for metabolic liver diseases was negative, as were tests for viral hepatitis. Antinuclear antibody was positive at a titre of 1:5210, with a speckled homogeneous pattern (NSP1). Rheumatoid factor was also positive ( $85 \mathrm{kU} / \mathrm{L}$; normal lower than $20 \mathrm{kU} / \mathrm{L})$. Anti-smooth muscle, antineutrophil cytoplasmic antigen, immunoglobulin A antitransglutaminase and antimitochondrial antibodies were negative. Serum immunoglobulin levels were all normal. Ultrasound of the liver was normal. Percutaneous liver biopsy was performed. The biopsy core $(2 \mathrm{~cm})$ included 17 portal areas; seven were expanded by a monotonous infiltrate composed predominantly of small lymphocytes. There was no parenchymal infiltrate. Bile ducts within

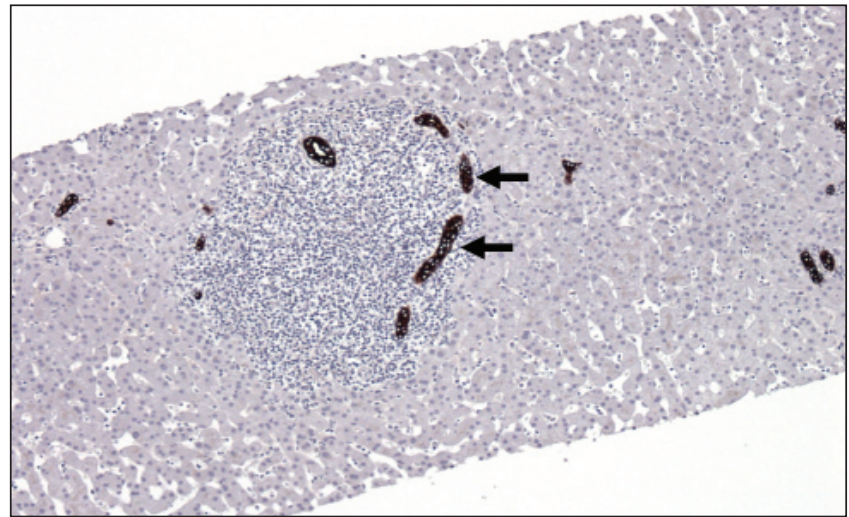

Figure 1) Liver core biopsy stained with cytokeratin 19 (CTK19) demonstrating a portal tract with chronic lymphocytic leukemia infiltration and bile ducts (black arrows) pushed toward the periphery of the portal tract (original magnification $\times 10$ ) lymphocyte-infiltrated portal spaces were pushed toward the periphery (Figure 1). Of note, four bile ducts showed distinct lymphocytic infiltration within the biliary epithelium (cholangiopathy), resulting in a significant narrowing of the bile duct lumen (Figures 2 and 3). The lymphocytic infiltrate was further characterized by immunohistochemical staining for the following: CD3, CD5, CD10, CD20, CD23, Bcl-2, cyclin-D1 and Ki67. The results of the immunological staining profile were classical for CLL (the Bcl-2 staining is shown in Figure 4).

\section{DISCUSSION}

The association of B-cell CLL and bile duct damage has not been previously reported. The patient was treated with a combination of fludarabine $\left(40 \mathrm{mg} / \mathrm{m}^{2}\right.$ orally on days 1 to 3 , intravenous cyclophosphamide $750 \mathrm{mg} / \mathrm{m}^{2}$ on day 1 , and intravenous rituximab $375 \mathrm{mg} / \mathrm{m}^{2}$ on day 1). One month later, all liver biochemical tests had completely normalized except for a persistent mild increase in serum gamma-glutamyl transferase level (73 U/L).

CLL is the most common leukemia (1) and has a variable clinical course, which can range from years of asymptomatic survival to rapid progression (2). Fifteen per cent to $27 \%$ of all hematological

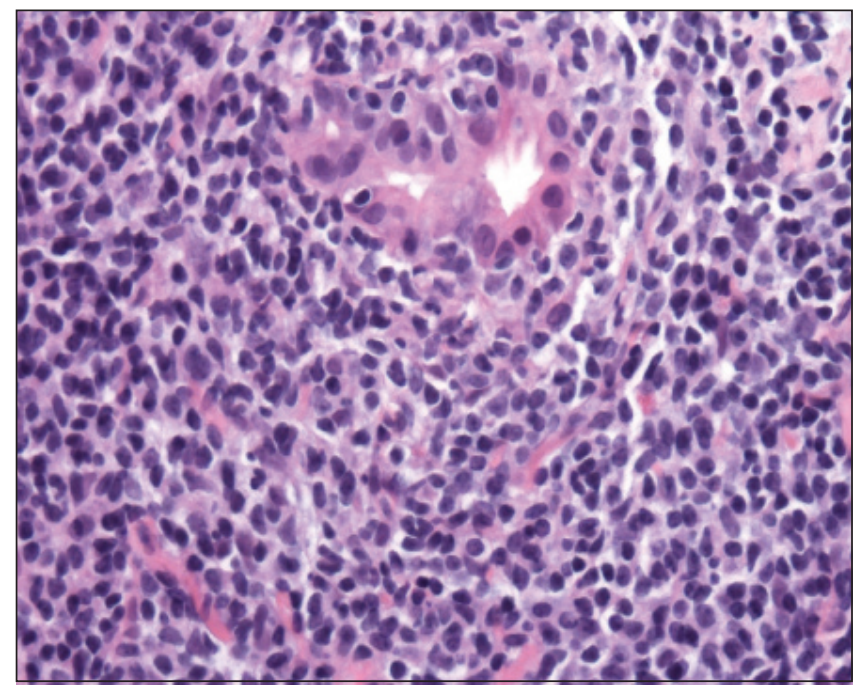

Figure 2) A hematoxylin and eosin-stained liver core biopsy section showing multiple small lymphocytes invading the bile duct epithelium with reactive changes in the biliary epithelium and lumen loss (original magnification $\times 40$ )

${ }^{1}$ University of Birmingham Medical School, Birmingham, United Kingdom; ${ }^{2}$ Department of Pathology, Calgary Laboratory Services; ${ }^{3}$ Division of Hematology and Hematological Malignancies; ${ }^{4}$ Liver Unit, Division of Gastroenterology, Department of Medicine, University of Calgary, Calgary, Alberta

Correspondence: Dr Mark G Swain, Division of Gastroenterology, Health Research Innovation Center, Room 4AA20, 3280 Hospital Drive,

Northwest, Calgary, Alberta T2N 4Z6. Telephone 403-220-3719, fax 403-210-9146, e-mail swain@ucalgary.ca

Received for publication May 9, 2011. Accepted May 16, 2011 


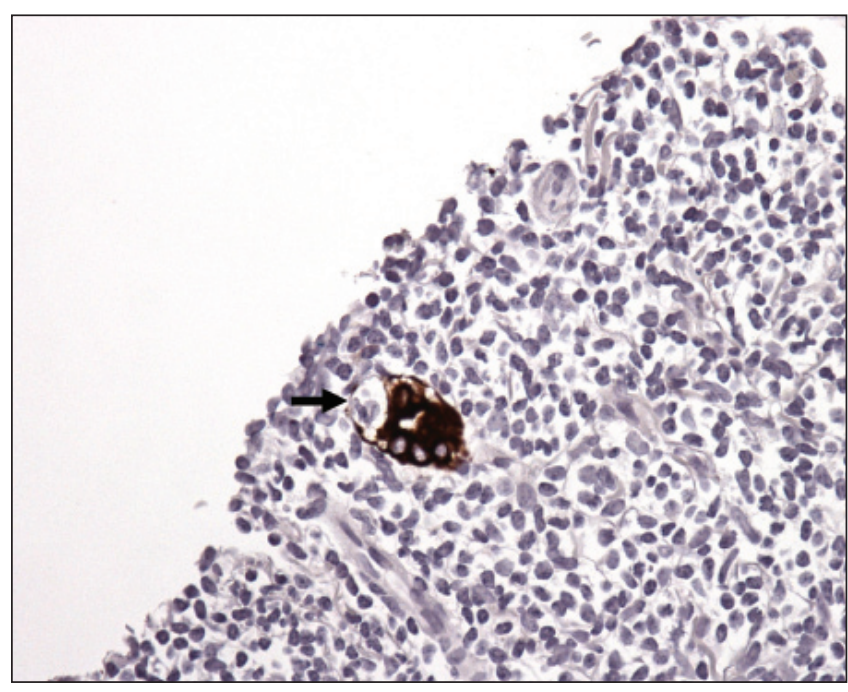

Figure 3) Bile duct stained with cytokeratin 19 (CTK19) (brown colour). The intraepithelial lymphocyte does not stain (black arrow) while the biliary epithelium stains strongly positive for CTK19 (original magnification $\times 40$ )

malignancies have liver involvement, which is diagnostic of stage IV disease (3). CLL can have a wide range of hepatic presentations (3). Baumhoer et al (3) analyzed liver biopsy specimens from 13 CLL patients and found portal infiltration in $77 \%$; however, bile duct lesions were not detected. In our patient, leukemic B-cells were clearly seen within the bile duct basement membrane and were associated with morphologically appearing apoptotic biliary epilethial cells. The biliary lesion we have described in the context of CCL could ultimately manifest as a vanishing bile duct syndrome, as was recently described for peripheral T cell lymphoma (4), and should be added to the differential diagnosis of cholangiopathy.

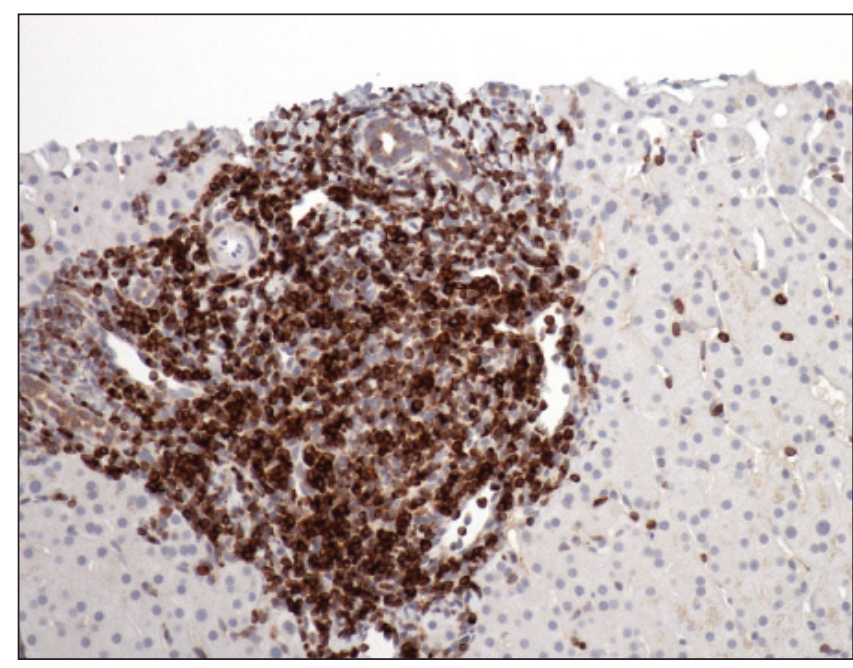

Figure 4) Lymphocytes within the portal spaces were strongly positive for Bcl-2. Bcl-2 positivity is illustrated by the brown stain (original magnification $\times 20$ )

\section{REFERENCES}

1. Jemal A, Siegel R, Ward E, Hao Y, Xu J, Thun MJ. Cancer statistics, 2009. CA Cancer J Clin 2009;59:225-49.

2. Boelens J, Lust S, Vanhoecke B, Offner F. Chronic lymphocytic leukaemia. Anticancer Res 2009;29:605-15.

3. Baumhoer D, Tzankov A, Dirnhofer S, Tornillo L, Terracciano LM. Patterns of liver infiltration in lymphoproliferative disease.

Histopathology 2008;53:81-90.

4. Gill RM, Ferrell LD. Vanishing bile duct syndrome associated with peripheral $\mathrm{T}$ cell lymphoma, not otherwise specified, arising in a posttransplant setting. Hepatology 2010;51:1856-7.

The Canadian Journal of Gastroenterology is now considering a limited number of submissions for IMAGE OF THE MONTH. These will be based on endoscopic, histological, radiological and/or patient images, which must be anonymous with no identifying features visible. The patient must consent to publication and the consent must be submitted with the manuscript. All manuscripts should be practical and relevant to clinical practice, and not simply a case report of an esoteric condition. The text should be brief, structured as CASE PRESENTATION and DISCUSSION, and not more than 700 words in length. A maximum of three images can be submitted and the number of references should not exceed five. The submission may be edited by our editorial team. 


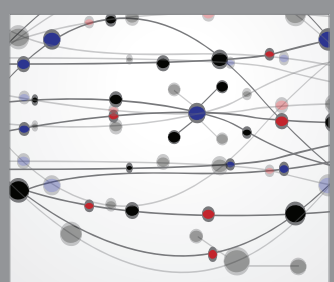

The Scientific World Journal
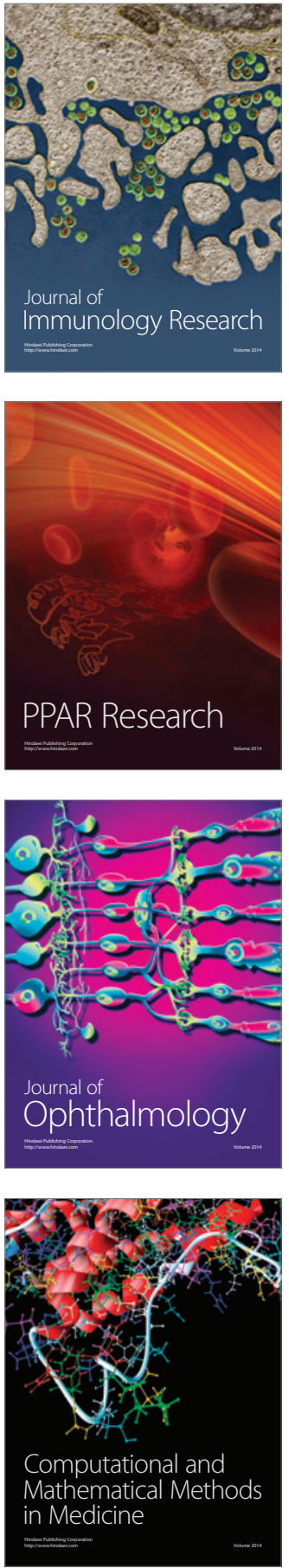

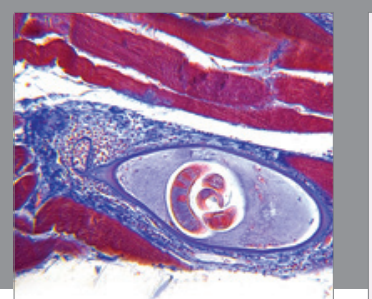

Gastroenterology Research and Practice

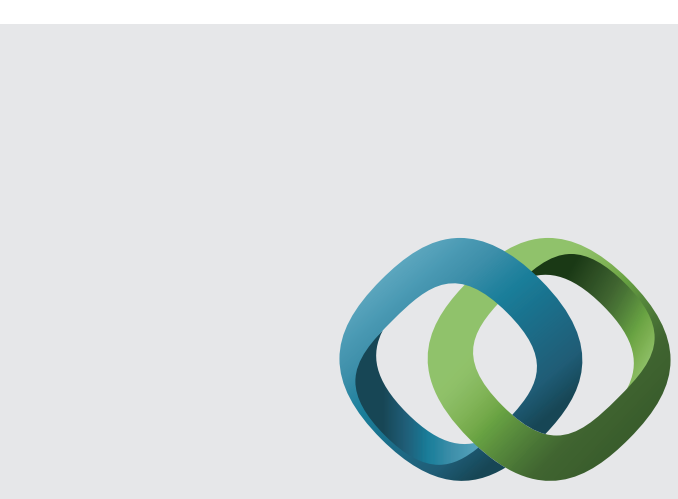

\section{Hindawi}

Submit your manuscripts at

http://www.hindawi.com
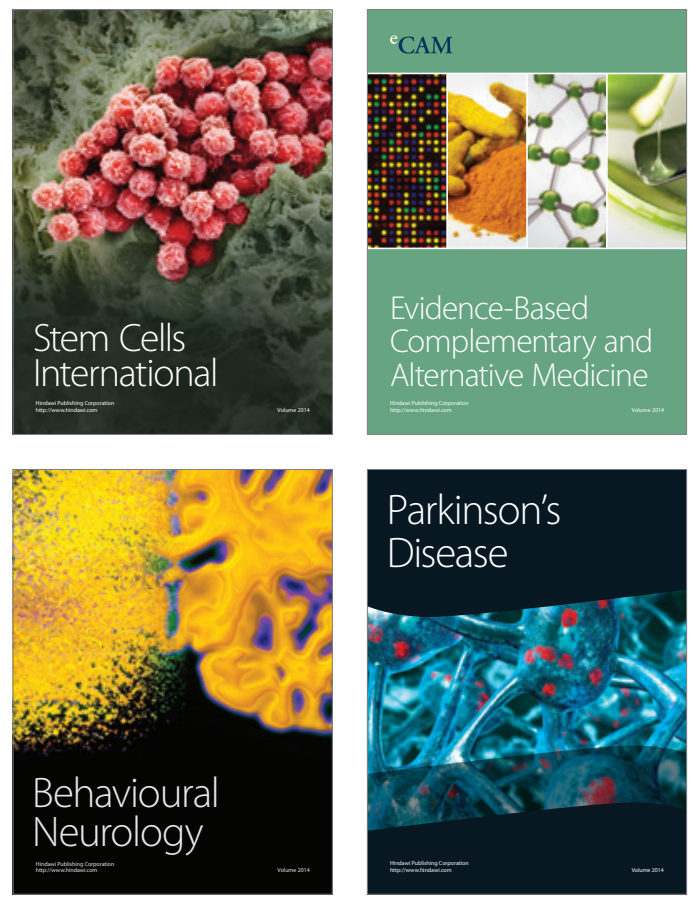
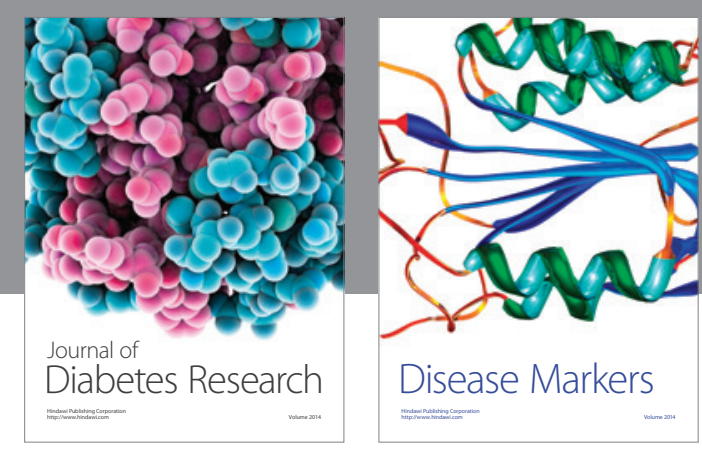

Disease Markers
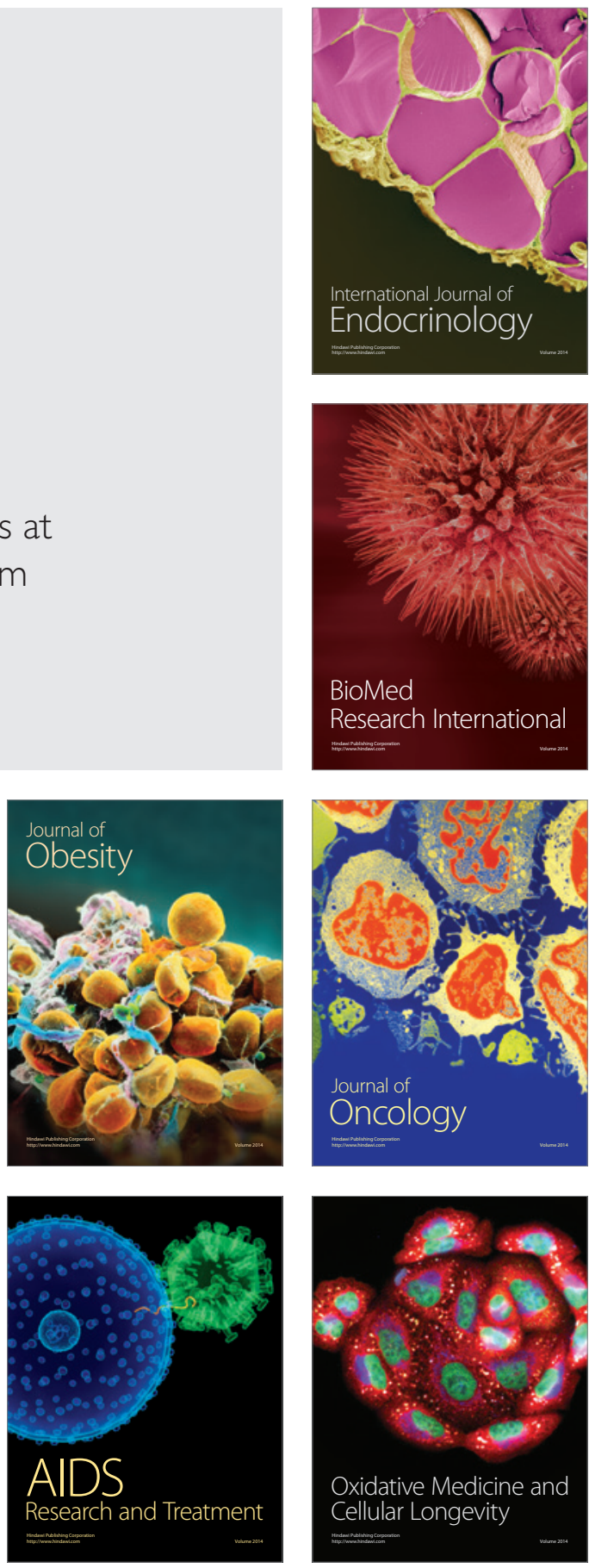